\title{
ANALISIS PERTUMBUHAN POPULASI BUDIDAYA IKAN SIDAT (Anguilla Marmorata) MELALUI KESTABILAN MODEL PERSAMAAN LOGISTIK DENGAN WAKTU TUNDA DAN PEMANENAN
}

\author{
R. Puragombo1, R. Ratianingsih ${ }^{2}$, dan A. I. Jaya ${ }^{3}$ \\ 1,2,3 Program Studi Matematika Jurusan Matematika FMIPA Universitas Tadulako \\ Jalan Soekarno-Hatta Km. 09 Tondo, Palu 94118, Indonesia. \\ 1ristapuragombo@yahoo.com, 2,3ratianingsih@yahoo.com
}

\begin{abstract}
Recently the existence of sidat in Lake Poso, Central Sulawesi, is in critical condition. A specific cultivation program is needed to preserve the existence of sidat cultivation. During the program, sidat sometimes comes to health problems that could postpone the harvesting. A Logistic growth model with time delay can be used to analyze the stability of sidat's harvesting. The model could be used to observe the extent of the effect of time delay with Pertubation Method. Using a fixed point iteration method, the relation between the delay time $(\tau)$ and the characteristic value $(\lambda)$ could be derived. The method gives to the best for delay time $(\tau)$ harvesting is $2-12$ week. The result is considered from the change rate of the characteristic value that must be kept in a small value such that the harvesting of sidat could recovered from illness. It could be done simultaneously with the harvesting stage I on the $16^{\text {th }}$ week.
\end{abstract}

Keywords : Fixed Point Iteration Method, Linearization, Logistic Growth Model with Time Delay and Harvesting, Pertubation Method, Stability

\begin{abstract}
ABSTRAK
Keberadaan sidat di Sulawesi Tengah khususnya Danau Poso saat ini dalam kondisi kritis. Salah satu cara penanggulangan kepunahan sidat di Sulawesi Tengah yaitu dengan cara budidaya. Selama kegiatan budidaya berlangsung, sidat rentan mengalami gangguan kesehatan, sehingga mengakibatkan pemanenan dapat tertunda. Model pertumbuhan logistik dengan waktu tunda dapat digunakan untuk menganalisis stabilitas pemanenan pada budidaya ikan sidat dengan metode pertubasi, sehingga dapat diketahui sejauh mana pengaruh waktu tunda pada pemanenan ikan sidat. Dengan metode iterasi titik tetap, dapat diperoleh hubungan antara waktu tunda ( $\tau$ ) dan nilai karakteristik $(\lambda)$ yang memberikan kesimpulan bahwa $\tau$ yang baik untuk model pertumbuhan logistik dengan waktu tunda dan pemanenan yaitu 2-12 yaitu kondisi dimana laju perubahan nilai karakteristik masih sangat kecil sehingga pemanenan ikan sidat yang terkena penyakit dan telah sembuh bisa dilakukan bersamaan dengan pemanenan tahap I pada minggu ke 16.
\end{abstract}

Kata Kunci : Kestabilan, Linearisasi, Metode iterasi Titik Tetap, Model Pertumbuhan Logistik dengan Waktu Tunda dan Pemanenan, Metode Pertubasi. 


\section{PENDAHULUAN}

\subsection{Latar Belakang}

Sebagai negara kepulauan terluas di dunia, dimana sekitar $70 \%$ wilayahnya terdiri dari perairan, Indonesia memiliki potensi pada sektor perikanan yang sangat besar, baik ditinjau dari kuantitas maupun diversivitas. Potensi tersebut merupakan potensi ekonomi yang diperkirakan mencapai US\$ 82 miliar pertahun. Dengan potensi yang ada tersebut seharusnya meletakan sektor perikanan manjadi salah satu sektor riil yang potensial di Indonesia. Keadaan ini menyebabkan perlunya pengelolaan yang baik sehingga dapat memberikan kontribusi yang optimal dalam perekonomian Indonesia (Yuli Putra, 2008).

Salah satu sektor perikanan yang mendukung perekonomian di Sulawesi Tengah yaitu Ikan Sidat (Anguilla Marmorata). Keberadaan sidat di Sulawesi Tengah khususnya Danau Poso saat ini dalam kondisi kritis. Jika tidak segera ditangani, maka sangat dimungkinkan salah satu potensi perikanan yang sangat identik dengan Poso ini akan punah. Ancaman kepunahan sidat di Danau Poso pernah dikemukakan langsung tim peneliti dari Balai Penelitian Pemulihan dan Konservasi Sumber Daya Ikan Badan Litbang Kelautan dan Perikanan Kementrian Kelautan dan Perikanan RI. Tim yang saat ini dipimpin oleh DR Krismono M.Si menemukan adanya fakta ancaman kepunahan sidat. Diantara faktanya adalah jumlah populasi yang minim serta cara penangkapan oleh masyarakat yang kurang ramah lingkungan. Sistem dan cara tangkap sidat yang dilakukan masyarakat dengan cara memasang jaring perangkap di hulu sungai Poso menjadi salah satu penyebab kritisnya populasi sidat di Danau Poso. Jaring perangkap yang digunakan masyarakat mengakibatkan sidat tidak bisa turun ke laut untuk bertelur/reproduksi (Darma Metusala, 2013).

Salah satu cara penanggulangan kepunahan Sidat di Sulawesi Tengah yaitu dengan cara budi daya. Selama kegiatan budi daya berlangsung, Sidat rentan mengalami gangguan kesehatan, baik yang disebabkan oleh hama maupun penyakit. Penyakit yang kerap menyerang Sidat ini di antaranya penyakit white spot dan serangan hama Trichordina. Akibat serangan ini, tidak jarang Sidat yang dibudidayakan akan mengalami kematian (Ruslan Roy, 2013), oleh karena itu diperlukan suatu tindakan penanggulangan pada Sidat yang terkena white spot sehingga mengakibatkan pemanenan dapat tertunda karena menunggu hasil dari penanggulangan tersebut.

Model pertumbuhan logistik dengan waktu tunda dapat digunakan untuk menganalisis stabilitas pemanenan pada budidaya ikan sidat. Pada model tersebut penyakit white spot pada ikan sidat, dianggap sebagai faktor tunda $(\tau)$. Analisa kestabilan pada model 
pertumbuhan logistik dengan waktu tunda tersebut bermanfaat untuk memprediksi sejauh mana pengaruh waktu tunda pada pemanenan ikan sidat.

\subsection{Rumusan Masalah}

Berdasarkan latar belakang yang telah diuraikan di atas maka rumusan masalah yang dapat diangkat adalah bagaimana pengaruh waktu tunda $(\tau)$ terhadap kestabilan model pertumbuhan logistik dengan waktu tunda dan pemanenan.

\subsection{Tujuan}

Penelitian ini bertujuan untuk mengetahui pengaruh waktu tunda $(\tau)$ terhadap kestabilan model pertumbuhan logistik dengan waktu tunda dan pemanenan.

\subsection{Manfaat Penelitian}

Adapun manfaat yang dapat diperoleh dari penelitian ini adalah sebagai berikut :

1. Dapat diketahui bagaimana keberadaan populasi Sidat di Danau Poso.

2. Dapat diketahui waktu tunda yang berpengaruh terhadap model pertumbuhan logistik dengan waktu tunda dan pemanenan.

3. Secara umum untuk dijadikan referensi dalam mengembangkan penerapan-penerapan ilmu matematika, khususnya mata kuliah Sistem Dinamik.

\subsection{Asumsi Penelitian}

Adapun asumsi yang digunakan dalam penelitian ini adalah tingkat pemanenan kurang dari laju pertumbuhan populasi.

\section{METODE PENELITIAN}

Langkah-langkah yang dilakukan dalam penelitian ini yaitu

a. Memulai penelitian.

b. Mengambil data

c. Mengolah data

d. Merevisi Model Pertumbuhan Logistik dengan Pemanenan yang dipengaruhi oleh waktu tunda

e. Mengkaji kestabilan model pertumbuhan logistik dengan waktu tunda dan pemanenan

f. Memeriksa peran waktu tunda terhadap kestabilan titik kritis pada model pertumbuhan logistik dengan waktu tunda dan pemanenan

g. Melakukan simulasi numerik

h. Menyimpulkan hasil penelitian

i. Selesai 


\section{HASIL DAN PEMBAHASAN}

\subsection{Revisi Model Pertumbuhan Logistik dengan Waktu Tunda dan Pemanenan}

Laju pertumbuhan dan laju pemanenan ikan sidat secara berturut-turut adalah $g(N)=$ $r N\left(1-\frac{N}{K}\right)$ dan $h(N)=\varphi N(t)$, sehingga model pertumbuhan logistik dengan memperhatikan faktor penundaan dan pemanenan adalah :

$\frac{d(N)}{d t}=r N(t)\left(1-\frac{N(t-\tau)}{K}\right)-\varphi N(t)$

dimana $\varphi$ adalah tingkat pemanenan.

\subsection{Kestabilan Model Prtumbuhan Logistik dengan Waktu Tunda dan Pemanenan}

\subsubsection{Penentuan Solusi Kritis}

Solusi kritis sistem persamaan model pertumbuhan logistik dengan waktu tunda dan pemanenan diperoleh dari persamaan (1) dengan menentukan nilai turunannya sama dengan nol sebagai berikut :

$\frac{d N}{d t}=0$

$\Rightarrow r N(t)\left(1-\frac{N(t-\tau)}{K}\right)-\varphi N(t)=0$

$\Rightarrow N(t)=0$ atau $r\left(1-\frac{N(t-\tau)}{K}\right)-\varphi=0$

Persamaan (2) memberikan dua solusi kritis, yang pertama adalah $N(t)=0$, sedangkan solusi kritis kedua ditentukan sebagai berikut :

$r-r \frac{N(t-\tau)}{K}-\varphi=0$

$\Rightarrow N(t-\tau)=\frac{(r-\varphi)}{r} K$

\subsubsection{Analisa Kestabilan Solusi Kritis}

Kestabilan model pertumbuhan logistik dengan waktu tunda dan pemanenan dianalisa pada masing-masing solusi kritis dengan melakukan linearisasi di sekitar solusi $N(t)=0$ dan $N(t-\tau)=\frac{(r-\varphi)}{r} K$ dengan metode pertubasi.

a. Pertubasi di Sekitar Solusi $N(t)=0$

Pertubasi di sekitar solusi $N(t)=0$ dinyatakan sebagai :

$N(t)=0+\varepsilon N_{1}(t)$

dengan $\varepsilon N_{1}(t)$ adalah perubahan dari solusi kritis $N(t)=0$ dengan $\varepsilon$ adalah bilangan riil yang cukup kecil. Selanjutnya persamaan (4) disubtitusi ke persamaan (1) sehingga menghasilkan :

$\frac{\varepsilon d N_{1}(t)}{d t}=\varepsilon r N_{1}(t)\left(1-\frac{\varepsilon N_{1}(t-\tau)}{K}\right)-\varepsilon \varphi N_{1}(t)$
$\Rightarrow \frac{\varepsilon d N_{1}(t)}{d t}=\varepsilon r N_{1}(t)-\varepsilon r N_{1}(t) \frac{\varepsilon N_{1}(t-\tau)}{K}-\varepsilon \varphi N_{1}(t)$ 
dengan mengalikan $\frac{1}{\varepsilon}$ pada kedua ruas dalam persamaan (5) diperoleh :

$\frac{d N_{1}(t)}{d t}=r N_{1}(t)-r N_{1}(t) \frac{\varepsilon N_{1}(t-\tau)}{K}-\varphi N_{1}(t)$

Karena $\varepsilon$ cukup kecil maka suku $-r N_{1}(t) \frac{\varepsilon N_{1}(t-\tau)}{K}$ pada persamaan (6) juga menjadi bernilai kecil pula. Dengan demikian suku tak linier $-r N_{1}(t) \frac{\varepsilon N_{1}(t-\tau)}{K}$ dapat diabaikan dan diperoleh persamaan pendekatan yaitu :

$\frac{d N_{1}(t)}{d t}=r N_{1}(t)-\varphi N_{1}(t)=(r-\varphi) N_{1}(t)$

Mengingat persamaan (7) merupakan persamaan diferensial variabel terpisah maka solusi dari persamaan (7) dapat diselesaikan sebagai berikut :

$\frac{d N_{1}(t)}{N_{1}(t)}=(r-\varphi) d t$

Selanjutnya dengan mengintegralkan kedua ruas pada persamaan (8) diperoleh:

$\int \frac{d N_{1}(t)}{N_{1}(t)}=\int(r-\varphi) d t$

$\Rightarrow \ln N_{1}(t)=(r-\varphi) t+C, C=$ konstanta

$\Rightarrow N_{1}(t)=C e^{(r-\varphi) t} ; C:$ konstanta

Solusi yang dinyatakan pada persamaan (9) memperlihatkan bahwa untuk $r$ $\varphi>0$ yakni kondisi dimana laju pertumbuhan intrinsik melebihi tingkat pemanenan, berat massa bertumbuh secara eksponensial dan tidak mengarah ke solusi kritis $N(t)=0$. Nilai solusi pertubasi yang diperoleh akan semakin besar seiring dengan bertambahnya waktu. Gambaran keadaan di atas dapat diamati melalui simulasi dengan pemilihan nilai parameter $r=0,15$ dan $\varphi=0,075$ pada interval waktu $t \square[0, \ldots, 50]$ dan konstanta $C=17,5$, dengan bantuan software Maple 13 diperoleh Gambar 1.

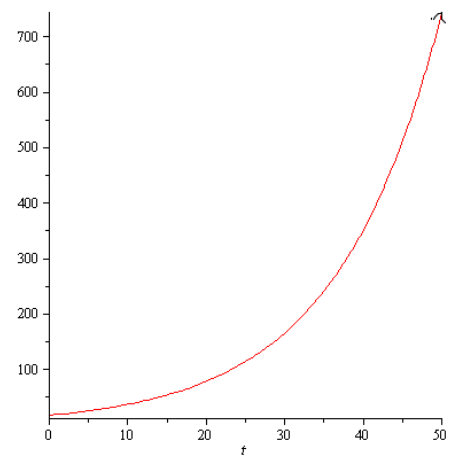

Gambar 1 : Grafik Pertumbuhan Solusi Pertubasi di Sekitar Solusi Kritis N(t) $=$ 0 untuk $(r-\varphi)>0$ 
Gambar 1 memperlihatkan bahwa setiap solusi pertubasi dengan keadaan awal $\mathrm{N}(0)>0$ akan meningkat seiring dengan bertambahnya waktu. Hal ini menunjukkan bahwa setiap solusi pertubasi akan bergerak meninggalkan solusi kritis $N(t)=0$. Dengan demikian dapat disimpulkan bahwa untuk $r-\varphi>0$, solusi kritis $N(t)=0$ adalah tidak stabil.

Untuk $r-\varphi<0$, yakni kondisi dimana tingkat pemanenan melebihi laju pertumbuhan intrinsik, persamaan (9) memperlihatkan bahwa berat massa menurun secara eksponensial dan mengarah ke titik kesetimbangan $N(t)=0$. Gambaran keadaan tersebut dapat diamati melalui simulasi dengan pemilihan nilai parameter $r=$ 0,15 dan $\varphi=0,3$ pada interval waktu $t \in[0, \ldots, 50]$ dan konstanta $C=17,5$, dengan bantuan software Maple 13, diperoleh Gambar 2 .

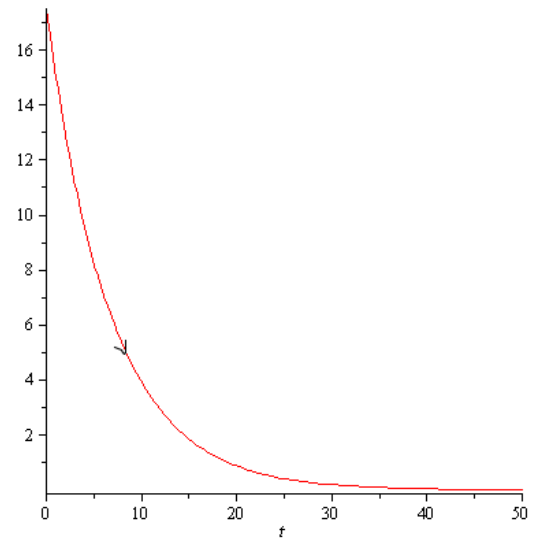

Gambar 2 : Grafik Pertumbuhan Solusi Pertubasi di Sekitar Solusi Kritis $N(t)=$ 0 untuk $(r-\varphi)<0$

Gambar 2 memperlihatkan bahwa setiap solusi pertubasi dengan keadaan awal $N(0)>0$ akan menurun seiring dengan bertambahnya waktu. Hal ini menunjukkan bahwa setiap solusi pertubasi akan bergerak mendekati solusi kritis $N(t)=0$. Dengan demikian dapat disimpulkan bahwa untuk $(r-\varphi)<0$, solusi kritis $N(t)=0$ adalah stabil.

b. Pertubasi di Sekitar Solusi $N(t)=\frac{(r-\varphi)}{r} K$

Pertubasi di sekitar solusi kritis $N(t)=\frac{(r-\varphi)}{r} K$ dinyatakan sebagai $N(t)=\frac{(r-\varphi)}{r} K+\varepsilon N_{1}(t)$

dengan $\varepsilon N_{1}(t)$ adalah perubahan solusi kritis $\square(\square)=\frac{(\square-\square)}{\square} \square$ dimana $\left|\square \square_{1}(\square)\right| \leq$ $\frac{(\square-\square)}{\square} \square$. Subtitusi persamaan (10) pada persamaan (1) memberikan : 


$$
\begin{aligned}
& \frac{d\left(\frac{(r-\varphi)}{r} K+\varepsilon N(t)\right)}{d t}=r\left(\frac{(r-\varphi)}{r} K+\varepsilon N(t)\right)\left(1-\frac{\left(\frac{(r-\varphi)}{r} K+\varepsilon N(t-T)\right)}{K}\right)-\varphi\left(\frac{(r-\varphi)}{r} K+\varepsilon N(t)\right) \\
& \frac{\varepsilon d N(t)}{d t}=((r-\varphi) K+\varepsilon r N(t))\left(1-\frac{\left(\frac{(r-\varphi)}{r} K+\varepsilon N(t-T)\right)}{K}\right)-\frac{(r-\varphi)}{r} \varphi K-\varepsilon \varphi N(t) \\
& \frac{\varepsilon d N(t)}{d t}=-\varepsilon(r-\varphi) N(t-T)-\frac{\varepsilon r N(t) \varepsilon N(t-T)}{K}
\end{aligned}
$$

Bila kedua ruas pada persamaan (11) dikalikan $\frac{1}{\varepsilon}$, dihasilkan :

$\frac{d N(t)}{d t}=-(r-\varphi) N(t-\tau)-\frac{r N(t) \varepsilon N(t-\tau)}{K}$

karena $\varepsilon$ cukup kecil maka bentuk tidak linier $-\frac{r N(t) \varepsilon N(t-\tau)}{K}$ pada persamaan (12) juga cukup kecil, dengan demikian bentuk $-\frac{r N(t) \varepsilon N(t-\tau)}{K}$ dapat diabaikan dan diperoleh persamaan pendekatan berikut :

$\frac{d N(t)}{d t}=-(r-\varphi) N(t-\tau)$

Dengan mengasumsikan solusi yang berbentuk eksponensial yaitu $N(t)=C e^{\lambda t}$, maka persamaan karakteristik dapat diperoleh dengan mensubtitusi $N(t)=C e^{\lambda t}$ ke dalam persamaan (13), sehingga menjadi :

$\frac{d e^{\lambda t}}{d t}=-(r-\varphi) e^{\lambda(t-\tau)}$

$\Rightarrow \lambda+(r-\varphi) e^{-\lambda \tau}=0$

Persamaan (14) memperlihatkan bahwa akar karakteristik $\lambda$ merupakan solusi dari persamaan tak linier yang dapat ditentukan dengan menggunakan metode iterasi titik tetap. Metode ini dipilih dengan mempertimbangkan bahwa fungsi $f(\lambda)$ adalah fungsi nonlinier.

$\mathrm{f}(\lambda)=\lambda+(\mathrm{r}-\varphi) \mathrm{e}^{-\lambda \tau}$

$\lambda=-(\mathrm{r}-\varphi) \mathrm{e}^{-\lambda \tau}$

$\mathrm{g}(\lambda)=-(\mathrm{r}-\varphi) e^{-\lambda \tau}$

Iterasi I

$\lambda_{0}=1, g\left(\lambda_{0}\right)=-(r-\varphi) e^{-\tau}$

Iterasi II

$\lambda_{1}=-(r-\varphi) e^{-\tau}, g\left(\lambda_{1}\right) \quad=-(r-\varphi) e^{-\left(-(r-\varphi) e^{-\tau}\right) \tau}$

$=-(r-\varphi) e^{(r-\varphi) \tau e^{-\tau}}$

Iterasi III

$$
\begin{aligned}
\lambda_{2}=-(r-\varphi) e^{(r-\varphi) \tau e^{-\tau}}, g\left(\lambda_{2}\right) & =-(r-\varphi) e^{-\left(-(r-\varphi) e^{(r-\varphi) \tau e^{-\tau}}\right) \tau} \\
& =-(r-\varphi) e^{(r-\varphi) \tau e^{(r-\varphi) \tau e^{-\tau}}}
\end{aligned}
$$


Iterasi IV

$\lambda_{3}=-(r-\varphi) e^{(r-\varphi) \tau e^{(r-\varphi) \tau e^{-\tau}}}, g\left(\lambda_{3}\right)=-(r-\varphi) e^{(r-\varphi) \tau e^{(r-\varphi) \tau e^{(r-\varphi) \tau} e^{-\tau}}}$

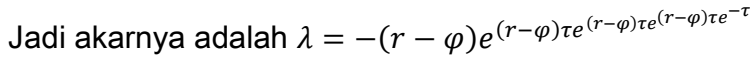

Mengingat $N(t)=C e^{\lambda t}$ adalah fungsi eksponensial maka tanda dari nilai $\lambda$ pada persamaan (15) adalah penentu kestabilan. Jika $\lambda<0$ maka solusi kritis $N(t-\tau)=$ $\frac{(r-\varphi)}{r} K$ akan stabil, sedangkan jika $\lambda>0$ maka solusi kritis $N(t-\tau)=\frac{(r-\varphi)}{r} K$ tidak stabil. Dengan demikian pengaruh waktu tunda terhadap model pertumbuhan logistik dengan waktu tunda dan pemanenan dapat diidentifikasi melalui nilai $\tau$ pada persamaan (15).

\subsection{Kestabilan Solusi Kritis $N(t-\tau)=\frac{(r-\varphi)}{r} K$}

Pada bagian ini akan diperiksa kestabilan solusi $N(t-\tau)$ untuk suatu nilai $\tau$. Pertama kali akan diamati nilai $\tau=0$ pada persamaan (15). Pengambilan nilai ini akan memberikan persamaan berikut :

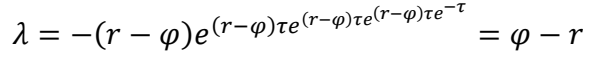

mengingat $r$ adalah laju pertumbuhan intrinsik dari model pertumbuhan logistik dan $\varphi$ adalah tingkat pemanenan maka persamaan (16) memberikan tafsiran bahwa solusi persamaan logistik tidak menunjukan adanya waktu tunda karena hanya di pengaruhi oleh $r$ dan $\varphi$ saja. Dari persamaan (16) terlihat pula bahwa solusi persamaan (13) menjadi $N(t)=C e^{-(r-\varphi) t}$. Hal ini berarti bahwa untuk $\tau=0$, solusi $N(t)$ mendekati nol atau dapat dikatakan bahwa solusi kritis $N(t-\tau)=\frac{(r-\varphi)}{r} K$ adalah stabil untuk nilai $(r-\varphi)>0$ dan tidak stabil untuk $(r-\varphi)<0$. Untuk menggambarkan keadaan tersebut, dipilih nilai $(r-\varphi)>0$ yaitu $r=0,15$ dan $\varphi=$ 0,075 , untuk keadaan $(r-\varphi)<0$ dipilih nilai $r=0,15$ dan $\varphi=0,3$ pada interval waktu $t \epsilon[0, \ldots, 50]$ dimana $t$ menunjukkan waktu dalam seminggu dan konstanta $C=17,5 \mathrm{gram}$, dengan bantuan software Maple 13 diperoleh Gambar 3 dan Gambar 4.

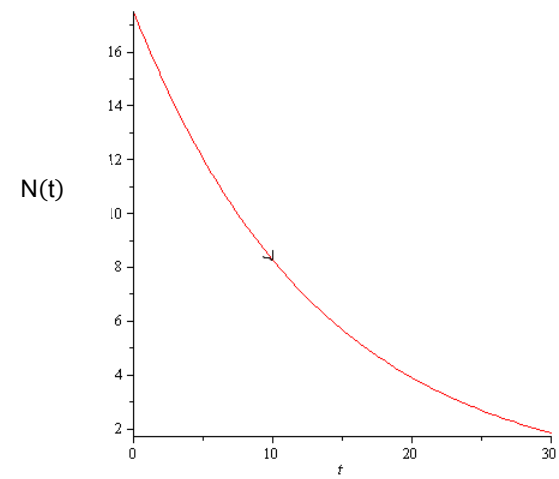

Gambar $3 \quad$ : Kestabilan Solusi Kritis $N(t-\tau)=\frac{(r-\varphi)}{r} K$ untuk $\tau=0$ dengan $r=0,15$ dan $\varphi=0.075$ 


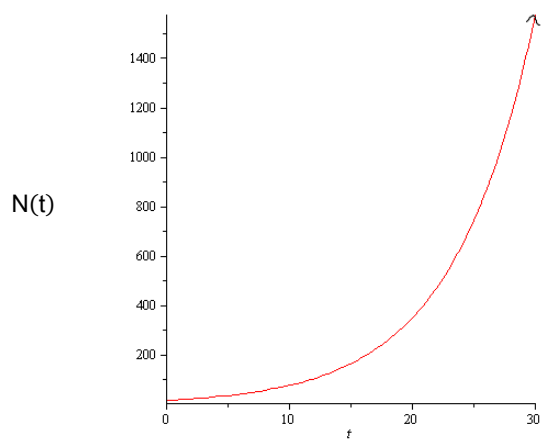

Gambar $4 \quad$ : Kestabilan Solusi Kritis $N(t-\tau)=\frac{(r-\varphi)}{r} K$ untuk $\tau=0$ dengan $r=0,15$ dan $\varphi=0,3$

3.4. Memeriksa Peran Waktu Tunda Terhadap Kestabilan Solusi Kritis $N(t-\tau)=\frac{(r-\varphi)}{r} K$

Selanjutnya akan diamati kestabilan solusi $N(t-\tau)$ untuk $\tau \neq 0$. Mengingat nilai $\tau<0$ tidak memiliki arti, maka akan ditinjau keadaan $\tau>0$. Untuk $\tau=2$ yaitu waktu tunda selama 2 minggu, $r=0,15$ dan $\varphi=0,075$ maka persamaan (15) memberikan tabel hubungan antara $\tau$ dan $\lambda$ sebagai berikut :

Tabel $1 \quad$ : Hubungan $\tau$ dan $\lambda$

\begin{tabular}{|c|c|c|}
\hline$\tau$ & $\lambda$ & Selisih $\lambda\left(\tau_{i}-\tau_{i+2}\right)$ \\
\hline 2 & $-0,089$ & 0,024 \\
\hline 4 & $-0,113$ & 0,039 \\
\hline 6 & $-0,152$ & 0,0718 \\
\hline 8 & $-0,2238$ & 0,14317 \\
\hline 10 & $-0,36697$ & 0,319211 \\
\hline 12 & $-0,686181$ & 2,523209489 \\
\hline 14 & $-1,5072235$ & 9.667671251 \\
\hline 16 & $-4,030432989$ & \\
\hline 18 & $-13,69810424$ & \\
\hline
\end{tabular}

Dengan bantuan software Maple 13, hubungan antara $\tau$ dan $\lambda$ pada tabel 1 dapat digambarkan sebagai berikut :

$\lambda$

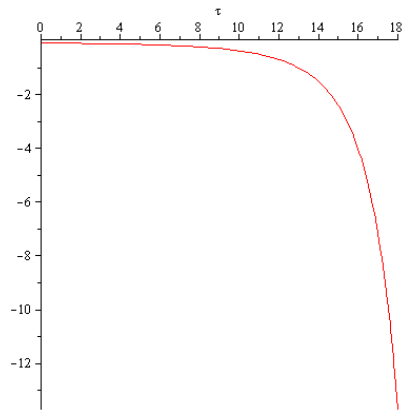

Gambar 5 : Hubungan antara $\tau$ dan $\lambda$ 
Melalui Tabel 1 Pengaruh $\tau$ pada model pertumbuhan logistik dengan waktu tunda dan pemanenan menentukan nilai $\lambda$. Semakin besar $\tau$ maka nilai $\lambda$ akan semakin kecil. Jika waktu tunda terjadi 2 - 12 minggu yaitu kondisi dimana laju perubahan nilai karakteristik masih sangat kecil, pemanenan ikan sidat yang terkena penyakit dan telah sembuh bisa dilakukan bersamaan dengan pemanenan tahap I pada minggu ke 16. Semakin kecil $\tau$ atau $\tau<16$ maka keadaan akan semakin baik untuk pemanenan, sebaliknya jika semakin besar atau $\tau>$ 16 maka pemanenan tahap I akan terlewati, dimana pada minggu ke 16 berat massa sidat sudah siap konsumsi.

\section{KESIMPULAN}

Dari hasil penelitian yang telah dilakukan penulis mengambil kesimpulan bahwa:

1. Solusi kritis $N(t-\tau)=\frac{(r-\varphi)}{r} K$ akan stabil jika nilai $(r-\varphi)>0$.

2. Pengaruh waktu tunda $(\tau)$ terhadap kestabilan model pertumbuhan logistik dengan waktu tunda dan pemanenan yaitu jika waktu tunda $(\tau)$ terjadi selama 2-12 minggu yaitu kondisi dimana laju perubahan nilai karakteristik masih sangat kecil, maka pemanenan ikan sidat yang terkena penyakit dan telah sembuh bisa dilakukan bersamaan dengan pemanenan tahap I pada minggu ke 16.

\section{DAFTAR PUSTAKA}

[1]. Henny, M, Timuneno, R, Heri Soelistyo Utomo, dan Widowati. 2008. Model Pertumbuhan Logistik Dengan Waktu Tunda. https II www.google.com /search? q=model_waktu_tunda). Diakses 25 Oktober 2013.

[2]. Indra J. A, Ratianingsih R. 2011. Buku Ajar Metode Numerik. UNTAD. Palu.

[3]. Metusala D. 2013. Sidat di Danau Posos Terancam Punah. Penerbit Radar Sulteng. Palu.

[4]. Mukhlis A. 2012. Budidaya Sidat dan Penerapan CBIB pada Budidaya Sidat. Ppt. Poso.

[5]. Okmaniar. 2011. Mengkaji Kestabilan Titik Kritis Model Pertumbuhan Logistik dengan Waktu Tunda Melalui Kurva Parameter. UNTAD. Palu.

[6]. Ratianingsih R. 2011. Identifikasi Parameter Penentu Kestabilan Model Pertumbuhan Logistik dengan Waktu Tunda. UNTAD. Palu.

[7]. Roy R. 2013. Budi Daya Sidat. Penerbit PT Agromedia Pustaka. Jakarta.

[8]. Sutimin. 2006. Model Pemanenan Logistik dengan Daya Dukung Bergantung Waktu pada Budidaya Rumput Laut. UNDIP. Semarang. 
[9]. Yuli P, Dody. 2008. Peran Sektor Perikanan Dalam Perekonomian dan Penyerapan Tenaga Kerja Di Indonesia: Analisis Input-Output. (https: //www.google.com/ search? q=peran_sektor_perikanan_pada_perekonomian_di_indonesia\&ie=utf-8). Diakses 17 maret 2014. 